\title{
Susanne von Meiss, Bücherwelten. Von Menschen und Bibliotheken
}

\author{
Anne Saada
}

\section{OpenEdition}

Journals

Édition électronique

URL : http://journals.openedition.org/ifha/8655

DOI : $10.4000 /$ ifha. 8655

ISSN : 2198-8943

\section{Éditeur}

IFRA - Institut franco-allemand (sciences historiques et sociales)

\section{Référence électronique}

Anne Saada, "Susanne von Meiss, Bücherwelten. Von Menschen und Bibliotheken », Revue de l'IFHA [En ligne], Date de recension, mis en ligne le 01 février 2017, consulté le 24 septembre 2020. URL : http:// journals.openedition.org/ifha/8655; DOI : https://doi.org/10.4000/ifha.8655

Ce document a été généré automatiquement le 24 septembre 2020

(CIFHA 


\title{
Susanne von Meiss, Bücherwelten. Von Menschen und Bibliotheken
}

\author{
Anne Saada
}

\section{RÉFÉRENCE}

Susanne von Meiss, Bücherwelten. Von Menschen und Bibliotheken, Hildesheim:

Gerstenberg, 2011 (5édition), 256 p., 19,95€ 
Cet ouvrage s'adresse aux amateurs de bibliothèques aussi bien anciennes que contemporaines. C'est à l'esthétique des bibliothèques que Susanne von Meiss s'intéresse, et plus précisément aux rapports que les hommes entretiennent avec leur bibliothèque, alors que les ouvrages sur les bibliothèques portent habituellement plus généralement sur l'histoire de ces institutions et la spécificité de leur collection. De ce point de vue, il s'agit plutôt d'un livre d'art, ce que les nombreuses et belles photos de Reno Guntli viennent confirmer. Son auteur écrit d'ailleurs pour des magazines d'art et de décoration intérieure comme

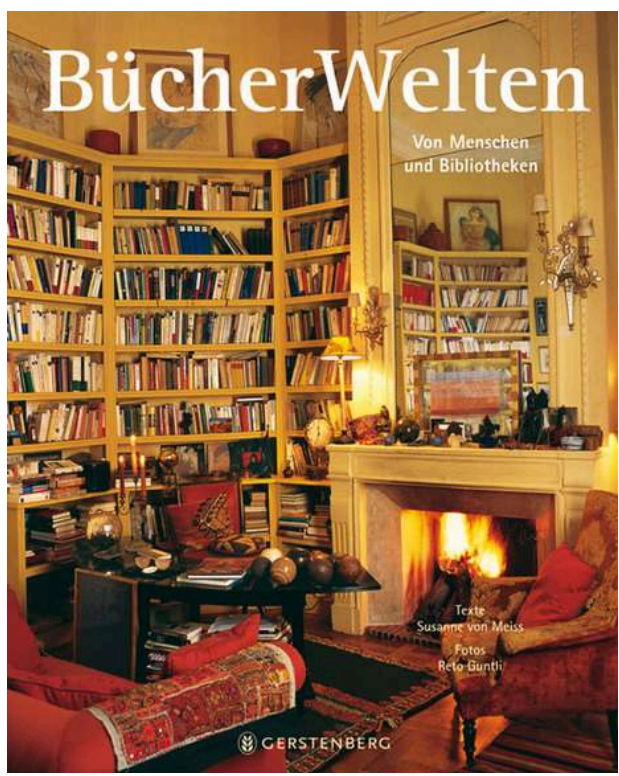
Vogue, Elle, Architectural Digest, revues pour lesquelles travaille également le photographe associé à cet ouvrage.

L'espace géographique considéré est aussi large que la chronologie : l'Europe, mais aussi le Brésil ; de même, on va des bibliothèques les plus anciennes aux collections les plus contemporaines. L'originalité de l'ouvrage réside dans les bibliothèques privées contemporaines qu'elle donne à voir, celles d'écrivains, d'éditeurs, d'agents littéraires, de critiques, de designers et d'artistes renommés.

L'ouvrage se divise en cinq chapitres thématiques. Chacun d'entre eux est présenté à travers différents exemples: les temples du livre (bibliothèques ecclésiastiques, bibliothèques princières, bibliothèques nationales) ; collectionner les livres (collections de particuliers, clubs, collections célèbres) ; vivre avec des livres (bibliothèques d'intérieur, chalets et pavillons de chasse, bibliothèques de designer) ; le livre et l'art (bibliothèques comme objets artistiques) ; le livre comme art ; les métiers du livre (l'art et l'artisanat, les antiquaires, les écrivains, les éditeurs, les agents et les critiques littéraires).

Il est amusant que les bibliothèques de professeurs manquent à ce panorama, vraisemblablement parce que les bibliothèques et les demeures de ces autres collectionneurs de livres ne sont pas assez belles - riches ? - pour entrer dans ce type d'ouvrages.

INDEX

Thèmes : Histoire de la culture

Index chronologique : Ouvrages transpériodiques 
AUTEURS

ANNE SAADA

CNRS - UMR 8547 